Article

\title{
Poly( $\beta$-hydroxyl amine)s: Valuable Building Blocks for Supramolecular Elastomers with Tunable Mechanical Performance and Superior Healing Capacity
}

\author{
Linlin Wang ${ }^{1,4}$, Jie Zhou ${ }^{1}$, Lei Li ${ }^{1,2, *(D)}$ and Shengyu Feng ${ }^{1,2,3}$ \\ 1 Key Laboratory of Special Functional Aggregated Materials, Ministry of Education, School of Chemistry and \\ Chemical Engineering, Shandong University, Jinan 250100, China; wll0218@sdu.edu.cn (L.W.); \\ w118810@sdu.edu.cn (J.Z.); fsy@sdu.edu.cn (S.F.) \\ 2 Shandong Key Laboratory of Advanced Silicone Materials and Technology, Shandong University, \\ Jinan 250100, China \\ 3 Key Laboratory of Colloid and Interface Chemistry, Ministry of Education, School of Chemistry and Chemical \\ Engineering, Shandong University, Jinan 250100, China \\ 4 Weihai New Era Chemical Co., Ltd., Weihai 264205, China \\ * Correspondence: lei.li@sdu.edu.cn
}

check for updates

Citation: Wang, L.; Zhou, J.; Li, L.; Feng, S. Poly( $\beta$-hydroxyl amine)s: Valuable Building Blocks for Supramolecular Elastomers with Tunable Mechanical Performance and Superior Healing Capacity. Polymers 2022, 14, 699. https://doi.org/ $10.3390 /$ polym 14040699

Academic Editor: Changwoon Nah

Received: 22 January 2022

Accepted: 10 February 2022

Published: 11 February 2022

Publisher's Note: MDPI stays neutral with regard to jurisdictional claims in published maps and institutional affiliations.

Copyright: (C) 2022 by the authors. Licensee MDPI, Basel, Switzerland. This article is an open access article distributed under the terms and conditions of the Creative Commons Attribution (CC BY) license (https:// creativecommons.org/licenses/by/ $4.0 /)$

\begin{abstract}
Supramolecular elastomers integrated with high mechanical toughness and excellent self-healing ability offer attractive applications in various fields such as biomedical materials and wearable electronics. However, the multistep preparation process for creating functional polymer precursors and the expensive stock materials required are two factors that limit the widespread use of supramolecular elastomers. Herein, for the first time, poly( $\beta$-hydroxyl amine)s generated by amineepoxy polymerization were used in the development of supramolecular polymer materials. Based on the novel silicon-containing poly( $\beta$-hydroxyl amine)s synthesized by the polymerization between 1,3-bis(3-glycidyloxypropyl)tetramethyldisiloxane and 3-amino-1,2-propanediol, dually cross-linked supramolecular elastomers with both hydrogen bonding and metal coordination were achieved, displaying adjustable mechanical properties with the tensile strength varying from $0.70 \mathrm{MPa}$ to 2.52 $\mathrm{MPa}$, respectively. Thanks to the dynamic nature of the supramolecular interactions, these elastomers exhibited favorable hot-pressing reprocessability and excellent self-healing performance, with the healing efficiency reaching up to $98 \%$ at $60{ }^{\circ} \mathrm{C}$ for $48 \mathrm{~h}$. Potential applications for photoluminescent materials and flexible electronic devices were demonstrated. We believe that its simplicity of synthesis, adjustable mechanical properties, and robust self-healing capacities bode well for future applications of this new supramolecular elastomer.
\end{abstract}

Keywords: dual-cross-linked elastomer; supramolecular elastomer; poly( $\beta$-hydroxyl amine); self-healing

\section{Introduction}

Supramolecular elastomers [1] are elastic networks cross-linked by non-covalent bonds such as hydrogen bonds [2,3], metal-ligand interactions [4,5], host-guest interactions [6,7], and $\pi-\pi$ stacking [8-10]. Due to the reversible nature of non-covalent interactions, supramolecular elastomers generally have excellent thermoplasticity, enhanced processability, and self-healing properties. Supramolecular elastomers are usually prepared based on one specific supramolecular interaction. Though the mono-cross-linking design is quite straightforward, the tunability of the material properties is limited by the variety of supramolecular interactions. Depending on the strength of the intermolecular interactions, the mechanical strength of the obtained materials ranges from a few tenths of MPa to tens of $\mathrm{MPa}$, while the healing occurs with or without external triggers. In order to improve the design flexibility, mechanical toughness, and self-healing properties of polymeric materials, a cooperative double cross-linking strategy has recently been explored by combining 
two orthogonal supramolecular interactions [11,12]. For example, both metal-coordinated bonds and hydrogen bonds have been introduced into the same polymer network, and the resulting elastomer can heal itself at room temperature while exhibiting excellent elasticity [13]. By combining strong and weak metal-ligand interactions through incorporating two potential ligands of $\mathrm{Fe}^{3+}$ ions, a dual-cross-linked polydimethylsiloxane network was reported, exhibiting tunable mechanical strength and self-healing ability [14]. In addition, dually associated supramolecular polymers containing both hydrogen bonding and metal coordination was demonstrated with enhanced fracture energy and exhibiting multiple shape-memory and self-healing properties [15]. Due to their rich chemical structures, adjustable mechanical properties, and self-healing capacities, supramolecular elastomers can potentially be used in the field of wearable electronics, electronic skins, motion tracking, and health monitoring [16-18]. Despite these great advances, the multistep preparation process for creating functional polymer precursors and the expensive stock materials required are two factors that limit the widespread use of supramolecular elastomers.

The polymerization between amine and epoxide functionalities is known to proceed under ambient conditions to provide poly ( $\beta$-hydroxyl amine)s. This reaction is catalyst-free and generates no by-product [19]. Its functional group tolerance allows for the synthesizing of a library of polymers with various functional groups from many commercially available amines. Because of these advantages, amine-epoxy polymerizations have been applied to synthesize multifunctional main-chain cationic polymers [19], hyperbranched polymers [20], porous materials [21], shape-memory materials [22], and zwitterionic hydrogels [23]. Our group has utilized this reaction to develop novel clickable and fluorescent silicon-containing poly( $\beta$-hydroxyl amine)s, which have been employed in reusable adhesives and reprocessable elastomers [24]. Poly( $\beta$-hydroxyl amine)s possess abundant hydroxyl groups with intrinsic hydrogen-bonding capabilities. Furthermore, repetitive nitrogen atoms in the polymeric backbone can provide lone pairs of electrons for coordination with electron-deficient metal ions. Both features make poly( $\beta$-hydroxyl amine)s promising candidates for the preparation of supramolecular polymer materials. This information inspired us to explore the use of poly( $\beta$-hydroxyl amine)s to design dually supramolecular elastomers with unique dynamic properties, such as self-healing and reprocessable capacities.

In this study, we designed a new type of silicon-containing poly( $\beta$-hydroxyl amine)s via the amine-epoxy polymerization between 1,3-bis(3-glycidyloxypropyl)tetramethyldisiloxane and 3-amino-1,2-propanediol. The obtained polymer possesses the low glass transition temperature of $-22{ }^{\circ} \mathrm{C}$, as well as abundant hydroxyl side groups. Due to the cumulative effect of weak hydrogen-bonding interactions, a stretchable, rehealable, and reprocessable hydrogen-bonded silicone elastomer was achieved. Additionally, introducing copper chloride resulted in a dual-cross-linked network formed by hydrogen bonds (hydroxy groups) and coordination bonds ( $\mathrm{Cu}^{2+}$ with nitrogen atoms) $[25,26]$, endowing our material with enhanced and adjustable mechanical properties. Thanks to the dynamic features of both supramolecular interactions, an excellent self-healing capacity was achieved in these dual-cross-linked elastomers. This research provides a feasible method for designing mechanically tough, self-healing, reprocessable materials that demonstrate promising applications for use in photoluminescent materials and flexible electronics. To our knowledge, this is the first attempt to use poly( $\beta$-hydroxyl amine) generated via the amine-epoxy polymerization for supramolecular materials.

\section{Materials and Methods}

\subsection{Materials}

1,3-Bis(3-glycidyloxypropyl)tetramethyldisiloxane (97\%) was purchased from Hwrk Chemical Co., Ltd. (Beijing, China). 3-Amino-1,2-propanediol (98\%) was supplied by Heowns Biochemical Technology Co., Ltd. (Tianjin, China). Copper chloride (anhydrous) was obtained from Energy Chemical Co., Ltd. (Shanghai, China). Europium nitrate hexahydrate $(99.99 \%)$ and chloroform-D $\left(\mathrm{CDCl}_{3}, 99.8 \%\right)$ were purchased from Aladdin Co., 
Ltd. (Shanghai, China). Methanol (AR grade), tetrahydrofuran (THF, AR grade), petroleum ether (AR grade), and chloroform (AR grade) were provided by Fuyu Fine Chemical Co., Ltd. (Tianjin, China). Multi-walled carbon nanotubes with an outer diameter of 4-6 nm (MWCNT) were obtained from Organic Chemicals Co., Ltd. (Chengdu, China) All the reagents and solvents were used as received.

\subsection{Characterization and Measurements}

The proton nuclear magnetic resonance $\left({ }^{1} \mathrm{H}\right.$ NMR) spectrum was analyzed on a Bruker Avance $400 \mathrm{MHz}$ spectrometer at $25^{\circ} \mathrm{C}$ with $\mathrm{CDCl}_{3}$ as the solvent and without tetramethylsilane (TMS) as the internal reference for chemical shifts $(\delta, \mathrm{ppm})$. The Fourier transform infrared spectrum (FT-IR) was recorded on a Bruker TENSOR 27 infrared spectrophotometer using the $\mathrm{KBr}$ pellet technique from the $4000 \mathrm{~cm}^{-1}$ to $500 \mathrm{~cm}^{-1}$. The resolution was $4 \mathrm{~cm}^{-1}$ and 16 scans with a heating rate of $3^{\circ} \mathrm{C} / \mathrm{min}$. Gel permeation chromatography (GPC) indices were detected with a Waters 1515 liquid chromatograph equipped with a 2414 refractive index detector. The column temperature was set at $40{ }^{\circ} \mathrm{C}$ and the flow rate of THF was stable at $1.0 \mathrm{~mL} / \mathrm{min}$. Differential scanning calorimetry (DSC) was measured using the TA Instruments SDTQ 600 under dry nitrogen flow, and the temperature range was from $-140{ }^{\circ} \mathrm{C}$ to $100{ }^{\circ} \mathrm{C}$, with a heating and cooling speed of $10{ }^{\circ} \mathrm{C} / \mathrm{min}$. For each specimen, two cooling-heating cycles were applied to eliminate thermal history, and the $\mathrm{T}_{\mathrm{g}}$ was obtained from the second cooling-heating process. The fluorescence (excitation and emission) spectra were performed on a Hitachi F-4500 fluorescence spectrophotometer using a monochromatic Xe lamp as an excitation source. Ultraviolet absorption spectra in a $\mathrm{CH}_{3} \mathrm{OH}$ solution were detected using a TU-1901 Dual Beam UV-Vis spectrophotometer in the wavelength range of 200-700 $\mathrm{nm}$. The transmittance spectra of the elastomer were also recorded by a TU-1901 Dual Beam UV-Vis spectrophotometer in the wavelength range of 200-700 nm. Narrow X-ray photoelectron spectroscopy (XPS) was performed using a Thermo Fisher Scientific (Waltham, MA, USA) ESCALAB 250 spectrometer with a monochromatic Al Kalph $(150 \mathrm{~W})$ source. The survey and high-resolution scans were generated at $200 \mathrm{eV}$ pass energy and $30 \mathrm{eV}$ pass energy, respectively. Scanning electronic microscopy images (SEM) and EDS (including elemental mapping) were obtained via a Quanta 250 FEG-SEM device (FEI, Lausanne, Switzerland), and the contents of some elements were recorded simultaneously. The specimens were cut and coated with a thin layer of platinum black before the investigation. Mechanical tensile tests (including the healing and reprocessing tests) of the elastic films were implemented using the Instron 3343 material testing system with a speed of $100 \mathrm{~mm} / \mathrm{min}$. For all the tensile tests, the films were cut into several dumbbell-shaped samples with a size of $40 \times 4 \times 0.8 \mathrm{~mm}^{3}$, and at least three parallel tests were conducted. The resistance of the conductive material during the stretching process (speed rate $=5 \mathrm{~mm} / \mathrm{min}$ ) was measured step by step using a CHINT ZTY0105A digital multimeter.

\subsection{Synthesis of Polymer P1 via the Amine-Epoxy Polymerization}

The mixture of 1,3-bis(3-glycidyloxypropyl)tetramethyldisiloxane (7 mmol, $2.544 \mathrm{~mL})$ and 3-amino-1,2-propanediol (7 mmol, $0.638 \mathrm{~g}$ ) was added to methanol ( $3 \mathrm{~mL})$, and stirred with a mechanical stirrer at $60{ }^{\circ} \mathrm{C}$ for $24 \mathrm{~h}$. Subsequently, the crude mixture was diluted with a small amount of THF and was slowly precipitated into a large amount of petroleum ether, repeated three times. After vacuum drying, the target $\mathbf{P 1}$ was obtained. $\left(M_{\mathrm{W}}=10,130\right.$, PDI = 2.10.)

\subsection{Preparation of the Hydrogen-Bonded Elastomer}

The solution of polymer P1 in methanol was poured into a Teflon plate mold, dried naturally at room temperature, then dried in a vacuum at $80{ }^{\circ} \mathrm{C}$ for $24 \mathrm{~h}$. Finally, the transparent hydrogen-bonded elastomer was obtained. 


\subsection{Preparation of Dually Supramolecular Elastomers (P1-Cu- $\mathbf{x} \mathbf{1})$}

Various amounts of $\mathrm{CuCl}_{2}$ were introduced into the $\mathbf{P 1}$ network to yield dually supramolecular elastomers named as $\mathbf{P 1 - C u - x / 1 , ~ w h e r e ~ t h e ~ m o l a r ~ r a t i o ~ o f ~ n i t r o g e n ~ a t o m s ~}$ vs. $\mathrm{CuCl}_{2}$ in $\mathbf{P 1}$ was $\mathrm{x} / 1$. The preparation of elastomer P1-Cu-3/1 is described as an example. To the solution of polymer P1 (2.26 g, $5 \mathrm{mmol}$ of nitrogen atoms, 1 eq.) in $2 \mathrm{~mL}$ of methanol, the solution of $\mathrm{CuCl}_{2}(22.4 \mathrm{mg}, 0.167 \mathrm{mmol}, 0.33$ eq.) in $1 \mathrm{~mL}$ of methanol was added. After stirring for $5 \mathrm{~min}$, the mixture was poured into a Teflon mold, dried naturally at room temperature, then dried in a vacuum at $80{ }^{\circ} \mathrm{C}$ for $24 \mathrm{~h}$ to remove the solvent. Finally, a blue stretchable film was obtained. Following a similar process, all the other dually supramolecular samples were prepared by adjusting the molar ratio of $\mathrm{CuCl}_{2}$ vs. nitrogen atoms.

\subsection{Hot-Pressing of the Supramolecular Elastomers}

The fractured materials of the elastic films were collected together and introduced into a steel mold $\left(150 \times 100 \times 0.5 \mathrm{~mm}^{3}\right)$, which was pressed at $50{ }^{\circ} \mathrm{C}$ for 20 min under $4 \mathrm{MPa}$. The tensile measurement was then performed to evaluated mechanical property of the material.

\subsection{Self-Healing Tests of the Supramolecular Elastomers}

The elastomer P1 or P1-Cu-6/1 was cut into dumbbell-shaped specimens with a size of $40 \times 4 \times 0.8 \mathrm{~mm}^{3}$. Each specimen was cut into halves using a blade. The two cut-off pieces were then instantly rejoined at the fracture surfaces and kept at either room temperature or $60{ }^{\circ} \mathrm{C}$ for different durations. Tensile measurements on the healed samples were conducted to quantitatively evaluate the self-healing efficiency, which is defined as the ratio of the tensile strength of the healed and original samples.

\subsection{Preparation of the Photoluminescent Supramolecular Elastomer P1-Eu-x}

Various amounts of $\mathrm{Eu}\left(\mathrm{NO}_{3}\right)_{3} \cdot 6 \mathrm{H}_{2} \mathrm{O}$ were introduced into the P1 network to yield photoluminescent supramolecular elastomers named as P1-Eu-x, where the molar ratio of $\mathrm{Eu}\left(\mathrm{NO}_{3}\right)_{3} \cdot 6 \mathrm{H}_{2} \mathrm{O}$ vs. nitrogen atoms in $\mathbf{P 1}$ was $\mathrm{x}$. Using the preparation of elastomer P1-Eu-20\% as an example, to the solution of polymer P1 $(1 \mathrm{~g}, 2.21 \mathrm{mmol}$ of nitrogen atoms, 1 eq.) in $12 \mathrm{~mL}$ of methanol, the solution of $\mathrm{Eu}\left(\mathrm{NO}_{3}\right)_{3} \cdot 6 \mathrm{H}_{2} \mathrm{O}(0.22 \mathrm{~g}, 0.442 \mathrm{mmol}, 0.2 \mathrm{eq}$. $)$ in $2 \mathrm{~mL}$ of methanol was added. After stirring at $40{ }^{\circ} \mathrm{C}$ for $4 \mathrm{~h}$, the mixture was poured into a Teflon mold, dried naturally at room temperature, then dried in a vacuum at $80{ }^{\circ} \mathrm{C}$ for $24 \mathrm{~h}$ to remove the solvent. Finally, a stretchable film was obtained. Following a similar process, all the other photoluminescent supramolecular elastomers were prepared by adjusting the molar ratio of $\mathrm{Eu}\left(\mathrm{NO}_{3}\right)_{3} \cdot 6 \mathrm{H}_{2} \mathrm{O}$ vs. nitrogen atoms.

\subsection{Preparation of the Conductive Supramolecular Elastomer P1-MWCNT}

To the mixture of $3.0 \mathrm{~g}$ of hydrogen-bonded polymer P1 in a certain amount of methanol, $10 \mathrm{wt} \%$ of multi-walled carbon nanotubes (MWCNT) was added uniformly and dispersed by ultrasound $\left(50{ }^{\circ} \mathrm{C}, 1.5 \mathrm{~h}\right)$. Afterwards, the mixture was poured into a Teflon mold, dried naturally at room temperature, then dried in a vacuum at $80{ }^{\circ} \mathrm{C}$ for $24 \mathrm{~h}$ to remove the solvent. Finally, the conductive supramolecular elastomer P1-MWCNT was obtained.

\section{Results}

Based on our previous work, poly( $\beta$-hydroxyl amine) was selected as the parent polymer to construct dual-cross-linked supramolecular elastomers. As shown in Scheme 1A, this functional polymer is readily prepared via the click polymerization of amine and epoxy monomers at ambient conditions. Along with its polymeric backbone, hydroxyl groups can form hydrogen bonds with each other, while nitrogen atoms with lone-pair electrons can effectively coordinate with metal ions. Both types of non-covalent interactions identify poly( $\beta$-hydroxyl amine) as a perfect candidate for constructing supramolecular materials 
(Scheme 1B). The mechanical behaviors of the obtained networks can be rationally tuned by regulating the metal ion content. Meanwhile, the dynamic natures of the hydrogen bond and the coordination bond give the elastomer outstanding self-healing capabilities.

(A)

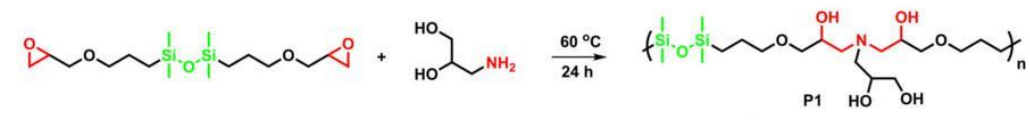

(B)

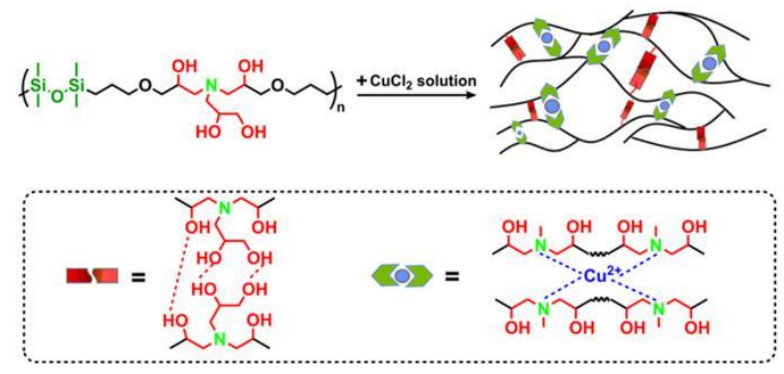

Scheme 1. (A) The synthesis of silicon-containing poly( $\beta$-hydroxyl amine) P1 via the amineepoxy polymerization between 1,3-bis(3-glycidyloxypropyl)tetramethyldisiloxane and 3-amino-1,2propanediol. (B) The preparation of supramolecular poly( $\beta$-hydroxyl amine) elastomers cross-linked with both hydrogen bonds (red polygons) and coordination bonds (green arrows and blue circles).

\subsection{Synthesis and Characterization of Polymer P1}

The parent polymer was synthesized by the amine-epoxy polymerization between commercially available 1,3-bis(3-glycidyloxypropyl)tetramethyldisiloxane and 3-amino1,2-propanediol. The former monomer with flexible siloxane units was selected to endow the obtained polymer with a low glass transition temperature, while the latter monomer with hydroxyl groups was selected to increase the density of the hydrogen bonds. The obtained polymer P1 was thoroughly investigated using ${ }^{1} \mathrm{H}$ NMR, FT-IR and GPC. Figure 1A shows the ${ }^{1} \mathrm{H}$ NMR spectra of monomer A and polymer P1. In the spectrum of 1,3-bis(3glycidyloxypropyl)tetramethyldisiloxane, the characteristic peaks of the epoxy protons appeared at 2.59, 2.78, and 3.13 ppm, which disappeared after polymerization with 3amino-1,2-propanediol. In the spectrum of $\mathbf{P 1}$, the proton resonances from the methylene groups $(\mathrm{g}, \mathrm{h})$ adjacent to the nitrogen atoms overlapped at 2.44-2.82 ppm, while those from the methyl groups (a) adjacent to the silicon atoms appeared at $0.01-0.07 \mathrm{ppm}$, indicating that the two target motifs were successfully introduced into the polymer chains. The integration ratio of the typical proton signals $\left(\mathrm{a}:(\mathrm{g}, \mathrm{h}):(\mathrm{d}, \mathrm{e}, \mathrm{f}, \mathrm{i}): \mathrm{j}: \mathrm{i}^{\prime}: \mathrm{e}^{\prime}=12: 6: 9: 1: 1: 2\right)$ was in accordance with the theoretical calculation, further confirming the expected polymer structure. Moreover, the FT-IR measurements in Figure 1B showed that the two stretching absorption peaks of the primary amine groups (approximately 3500 and $3400 \mathrm{~cm}^{-1}$ ) in 3-amino-1,2-propanediol and the peak of the epoxy groups $\left(915 \mathrm{~cm}^{-1}\right)$ in 1,3-bis(3glycidyloxypropyl)tetramethyldisiloxane disappeared after the polymerization. In addition, the GPC analysis of P1 showed a unimodal distribution with an $M_{\mathrm{W}}$ of $10,130 \mathrm{~g} / \mathrm{mol}$ and a polydispersity index of 2.1. These results confirm the successful synthesis of P1 via amine-epoxy polymerization.

Due to the presence of nitrogen atoms on the backbone, polymer P1 is expected to possess excellent coordination capabilities with electron-deficient metal ions. Therefore, UVvis spectroscopy was used to investigate its coordinating behavior with $\mathrm{CuCl}_{2}$ (Figure 2A). The UV-vis spectrum of polymer P1 exhibited a major absorption peak at around $231 \mathrm{~nm}$ and a minor one at around $291 \mathrm{~nm}$. With the addition of $\mathrm{CuCl}_{2}$, the former peak gradually decreased, while the latter almost disappeared. More importantly, a new absorption peak appeared at around $270 \mathrm{~nm}$, and its intensity constantly increased with the addition of $\mathrm{CuCl}_{2}$. The difference in UV-vis spectra indicates the change in the electronic environment of the nitrogen atoms and the new UV absorption band could be ascribed to the bonding 
$\sigma(\mathrm{N}) \rightarrow$ antibonding $\mathrm{d}_{\mathrm{x} 2-\mathrm{y} 2}(\mathrm{Cu})$ charge transfer (according to the literature), demonstrating the effective coordination between polymer $\mathbf{P 1}$ and the $\mathrm{Cu}^{2+}$ ions $[25,26]$.

(A)

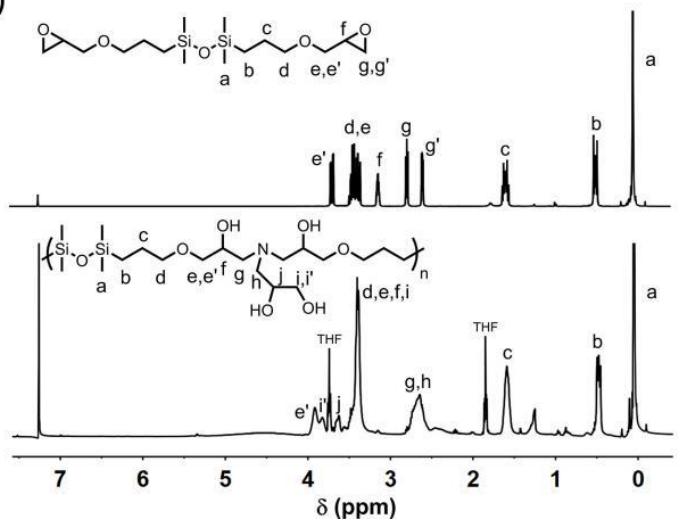

(B)

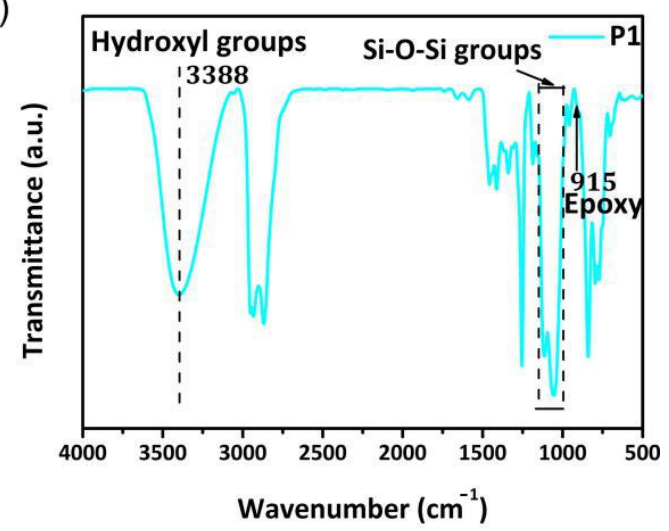

Figure 1. (A) The ${ }^{1} \mathrm{H}$ NMR spectra of 1,3-bis(3-glycidyloxypropyl)tetramethyldisiloxane (top) and polymer P1 (bottom). (B) The FT-IR spectrum of polymer P1.

(A)

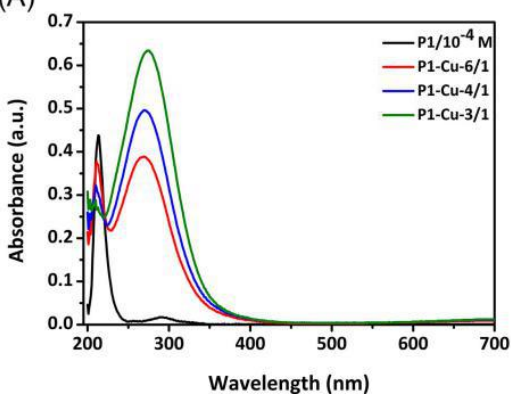

(B)

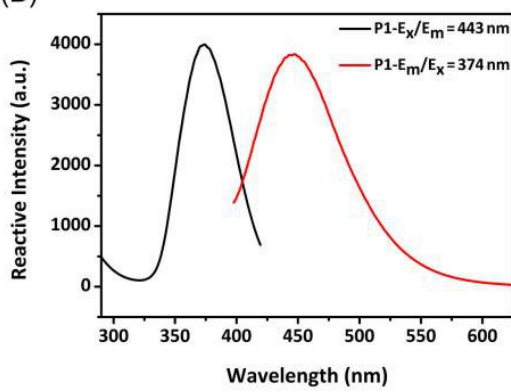

(C)

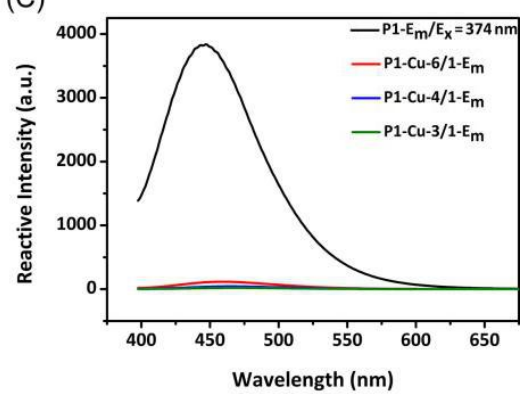

Figure 2. (A) The UV-vis spectra of polymers P1, P1-Cu-6/1, P1-Cu-4/1, and P1-Cu-3/1 in $\mathrm{CH}_{3} \mathrm{OH}$ ([N atom], $\left.10^{-4} \mathrm{M}\right)$. (B) The fluorescence excitation and emission spectra of polymer $\mathbf{P 1}$ in $\mathrm{CH}_{3} \mathrm{OH}$ ([N atom], 10 $\left.{ }^{-4} \mathrm{M}\right)$. (C) The fluorescence emission spectra of polymers P1, P1-Cu-6/1, P1-Cu-4/1, and P1-Cu-3/1 at the same excitation wavelength in $\mathrm{CH}_{3} \mathrm{OH}\left([\mathrm{N}\right.$ atom $\left.], 10^{-4} \mathrm{M}\right)$.

Unexpectedly, polymer P1 emits blue fluorescence under UV light at $365 \mathrm{~nm}$, even though it does not possess a conventional chromophore. Therefore, the excitation and emission spectra of $\mathbf{P 1}$ were studied to verify its fluorescent behavior. As illustrated in Figure 2B, the excitation wavelength appeared at $374 \mathrm{~nm}$, and the emission wavelength appeared at $447 \mathrm{~nm}$. This unconventional fluorescent phenomenon can be explained by the presence of $\mathrm{N} \rightarrow \mathrm{Si}$ coordination bonds in the polymeric backbones $[27,28]$. Photoluminescence would be generated by the through-space charge transfer from the lone electron pair in the nitrogen atoms to the $3 \mathrm{~d}$ empty orbital of the silicon atoms. Moreover, the $\mathrm{N} \rightarrow \mathrm{Cu}^{2+}$ coordination interactions could lead to new charge transfer, thereby weakening the original $\mathrm{N} \rightarrow$ Si coordination bonds, possibly inducing fluorescence quenching. To confirm this conjecture, fluorescent emission spectra were recorded after introducing $\mathrm{Cu}^{2+}$ into the $\mathbf{P 1}$ solution in methanol. As shown in Figure 2C, the fluorescence emission intensity clearly decreased with the increase of the $\mathrm{Cu}^{2+}$ content, indicating that this fluorescence quenching behavior was closely related to the $\mathrm{N} \rightarrow \mathrm{Cu}^{2+}$ coordination property of polymer $\mathbf{P 1}$.

\subsection{Hydrogen-Bonded and Metal-Coordinated Elastomers}

Since there are hydrogen-bonding interactions between hydroxyl groups and between hydroxyl groups and nitrogen atoms in polymer P1, it is expected that these interactions might behave as physical crosslinking points to provide hydrogen-bonded elastomers. In addition, introducing strong metal coordination bonds into the weak hydrogen bonding network would lead to hierarchical non-covalent bond networks, allowing the flexible 
adjustment of elastomer properties. Upon deformation, weak hydrogen bonds tend to effectively dissipate energy by dynamic association and disassociation, while the strong coordination bonds can maintain high tensile strength. Therefore, a series of P1 elastomers with various contents of $\mathrm{CuCl}_{2}$ were prepared.

According to the stress-strain curves shown in Figure 3A, the P1 elastomer showed the tensile strength of $0.70 \mathrm{MPa}$ and the elongation at break of $490 \%$, demonstrating the effective hydrogen-bonded crosslinking. Then various amounts of $\mathrm{CuCl}_{2}$ were introduced into the P1 network to yield dually supramolecular elastomers named as $\mathbf{P 1 - C u - x / 1}$, where the molar ratio of $\mathrm{CuCl}_{2}$ vs. nitrogen atoms in $\mathbf{P 1}$ was $1 / \mathrm{x}$. Upon adding $1 / 6$ eq. $\mathrm{CuCl}_{2}$ (vs. nitrogen atoms) to the polymer network, the tensile stress of the P1-Cu-6/1 sample was greatly increased up to $1.59 \mathrm{MPa}$, with the decrease of elongation at break to $337 \%$, indicating the formation of a more compact network with higher crosslinking density resulting from the metal coordination. The mechanical properties of these elastomers varied greatly with the $\mathrm{CuCl}_{2}$ molar ratios. When the amount of $\mathrm{CuCl}_{2}$ increased to $1 / 4$ eq., the tensile stress of the elastomer P1-Cu-4-1 reached 2.41 MPa, and the maximum tensile strain reached $287 \%$. With an increase of $\mathrm{CuCl}_{2}$ to $1 / 3$ eq., the large number of $\mathrm{CuCl}_{2}$ ions led to a heavily cross-linked polymer network. As a result, the P1-Cu-3-1 sample showed a tensile stress as high as $2.52 \mathrm{MPa}$, but the tensile strain decreased significantly to $268 \%$. Meanwhile, the introduction of $\mathrm{CuCl}_{2}$ also substantially increased the toughness and Young's modulus (E) of the elastomers. Among them, the P1-Cu-3-1 elastomer showed the highest toughness of $4.52 \mathrm{MJ} / \mathrm{m}^{3}$ and $\mathrm{E}$ of $4.69 \mathrm{MPa}$. These results demonstrate that the mechanical properties of these elastomers can be flexibly adjusted by tuning the $\mathrm{N} / \mathrm{CuCl}_{2}$ molar ratio in the polymer network.
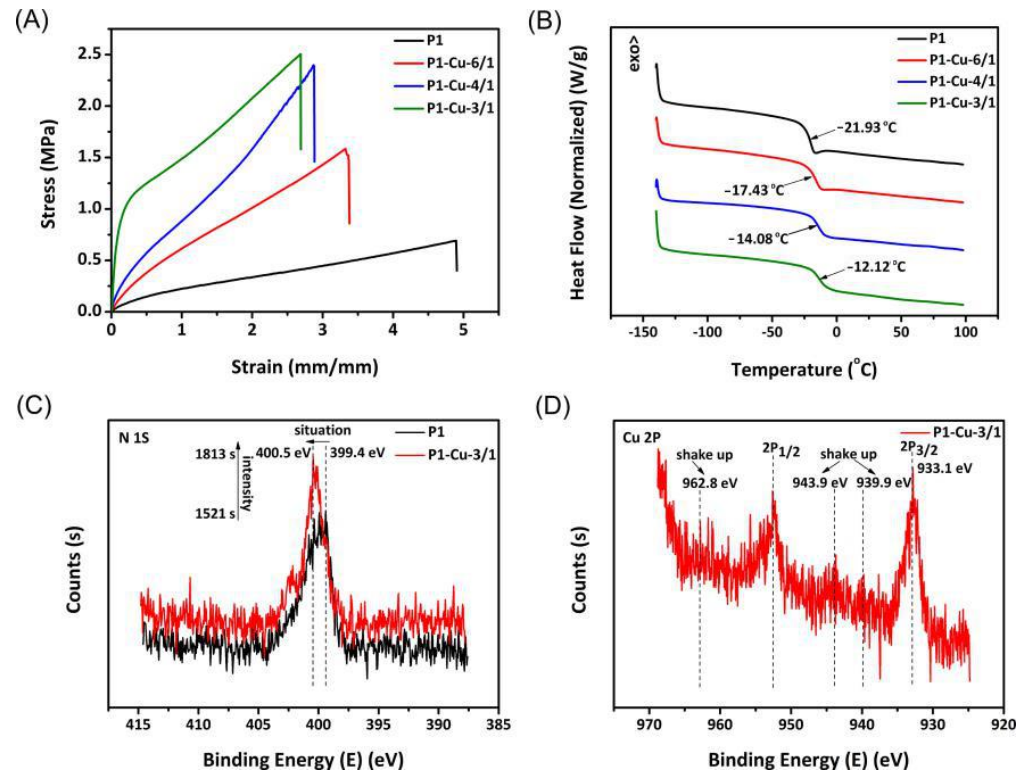

Figure 3. (A) The stress-strain curves and (B) differential scanning calorimetry curves of supramolecular elastomers P1 and P1-Cu. (C) The X-ray photoelectron spectrum of elastomers P1 and P1-Cu-3/1 in the $\mathrm{N} 1 S$ region. (D) The X-ray photoelectron spectrum of elastomer P1-Cu-3/1 in the Cu 2P region.

In addition to the mechanical properties, the thermal properties of the obtained elastomers were also significantly affected by the $\mathrm{Cu} / \mathrm{N}$ coordination. Due to the adequate flexibility of the siloxane backbones, the hydrogen-bonded elastomer P1 possesses a low glass transition temperature $\left(\mathrm{T}_{\mathrm{g}}\right)$ value; however, the introduction of $\mathrm{Cu}^{2+}$ can increase the degree of the crosslinking obtained elastomers, thus leading to the restriction of chain motion and hence, the increase of its $\mathrm{T}_{\mathrm{g}}$. The DSC results in Figure 3B showed that the $\mathrm{T}_{\mathrm{g}}$ of P1 was found at $-21.93^{\circ} \mathrm{C}$, whereas those of the metal-coordinated elastomers P1-Cu-6/1, P1-Cu-4/1 and P1-Cu-3/1 were measured at $-17.43{ }^{\circ} \mathrm{C},-14.08{ }^{\circ} \mathrm{C}$, and $-12.12{ }^{\circ} \mathrm{C}$, respectively. In addition to hydrogen bonding, the presence of coordination in the P1-Cu samples 
was believed to decrease the mobility of the polymer chains, therefore increasing the $T_{g}$ values. Meanwhile, no crystalline formation was observed for any elastomer under the studied experimental conditions, likely due to the poor crystallization ability of polymer P1.

To demonstrate the coordination between the nitrogen atoms and copper ions in the P1-Cu elastomers, narrow XPS analysis using a high resolution was applied to measure the change in binding energy after adding $\mathrm{CuCl}_{2}$ to the hydrogen-bonded elastomer. For P1-Cu-3/1, Figure $3 \mathrm{C}$ revealed that both the binding energy and intensity in the N $1 S$ region were greater than those of P1. Furthermore, there was a shoulder peak at $934.0 \mathrm{eV}$ for $\mathrm{Cu}$ $2 \mathrm{p}_{3 / 2}$ peaks (Figure $3 \mathrm{D}$ ), which could be attributed to the $\mathrm{Cu} / \mathrm{N}$ coordination complex, and the shake-up peaks at $939.9-943.9 \mathrm{eV}$ and at $962.8 \mathrm{eV}$ indicated the presence of partly coordinated $\mathrm{Cu}^{2+}[29,30]$. The charging of the electron cloud environments of the $\mathrm{N}$ and $\mathrm{Cu}$ atoms indicated that the lone pair electrons of the nitrogen atoms transferred to the empty orbitals of $\mathrm{Cu}^{2+}$ ions, contributing to the physical crosslinking of the obtained elastomers.

The surface morphology holds important theoretical and practical significance for elastomers; therefore, the surface topographies of $\mathbf{P 1}$ and P1-Cu-3/1 were observed via SEM. Figure $4 A, B$ showed that the introduction of coordination bonds did not affect the morphology of elastomers. A continuous and uniform surface morphology was observed, with no evidence of microphase separation, holes, or aggregation. This demonstrated that the coordination bonding between the poly( $\beta$-hydroxyl amine) matrix and metal ions was considerably strong, and high compatibility was observed inside the elastomers [31]. In addition, the element mapping obtained by EDS indicated that copper was successfully introduced into the supramolecular network and evenly distributed within the elastomer, similar to silicon (Figure 4C,D).
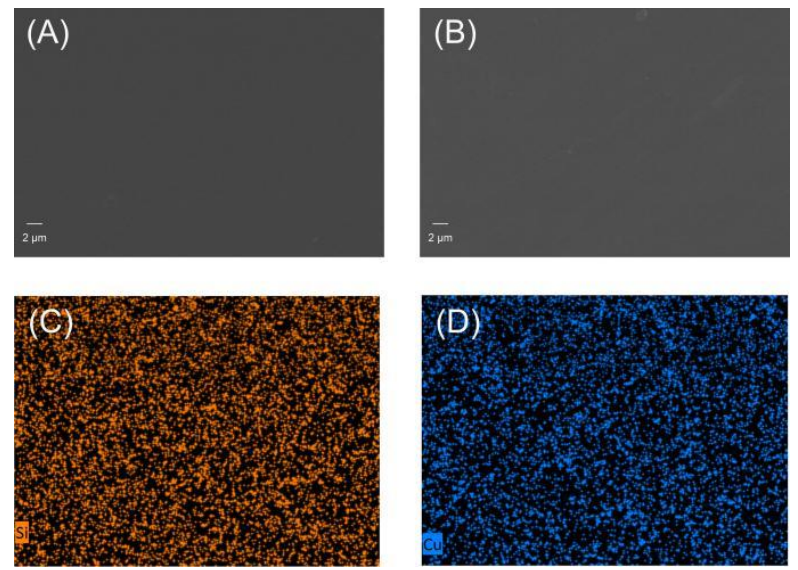

Figure 4. SEM images of elastomers P1 (A) and P1-Cu-3/1 (B). Elemental mappings of Si (C) and Cu (D) in elastomer P1-Cu-3/1 via EDS.

\subsection{Dynamic Properties of the Supramolecular Elastomers}

Considering the reversibility of the hydrogen bonds and coordination bonds, along with the excellent flexibility of polymer P1, both the hydrogen-bonded elastomer P1 and the metal-coordinated P1-Cu are expected to possess self-healing capabilities. To prove this hypothesis, the $\mathbf{P 1}$ or $\mathbf{P 1}-\mathbf{C u}-\mathbf{6} / \mathbf{1}$ specimen was cut in half using a blade. The obtained cut-off pieces were then rejoined at the fracture surfaces and incubated at either room temperature (RT) or $60^{\circ} \mathrm{C}$ for different durations. Figure $5 \mathrm{~A}$ clearly showed that the ruptured surface was completely healed, withstanding the tensile stress. The typical tensile stress-strain curves of the pristine and healed P1 and P1-Cu-6/1 elastomers are shown in Figure 5B,D, respectively. Their self-healing efficiency is defined as the ratio of the tensile strength of the healed sample to that of the pristine sample.

After being held at RT for $48 \mathrm{~h}$, the tensile strength and the strain at break of elastomer P1 were $0.38 \mathrm{MPa}$ and $340 \%$, respectively. As expected, the healing efficiency increased with the incubation time, manifested by $83 \%$ of tensile strength recovered after $96 \mathrm{~h}$ (Figure 5C). 
Heating was more effective in increasing the self-healing efficiency, which reached up to $98 \%$ at $60^{\circ} \mathrm{C}$ for $48 \mathrm{~h}$. Nearly complete recovery of the original tensile curve was observed in Figure 3B, demonstrating the excellent self-healing capability of P1. In contrast, the healing efficiency of P1-Cu-6/1 decreased to 94\% under the same conditions (Figure 5E) because the higher crosslinking degree led to a greater restriction of segmental movement.

(A)

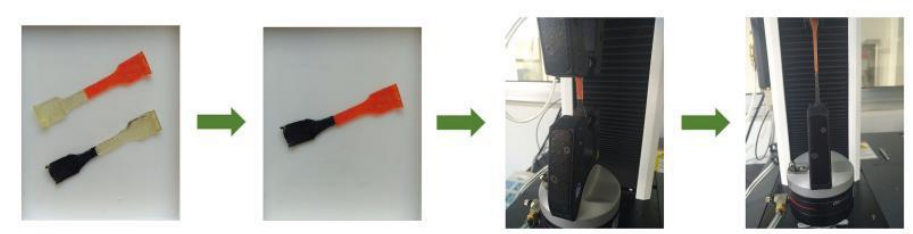

(B)

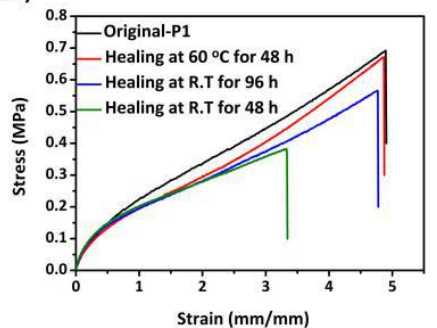

(D)

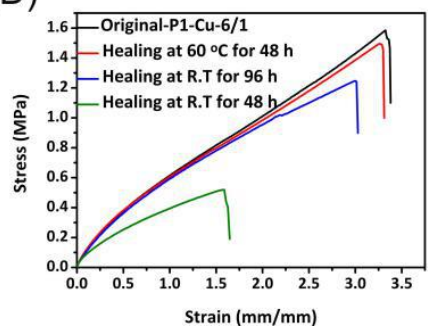

(C)

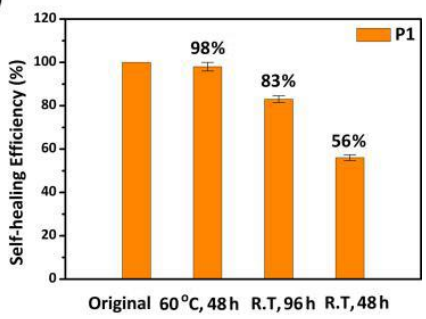

(E)

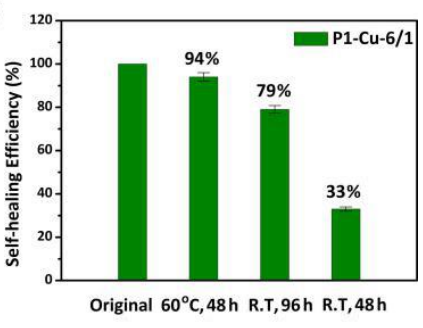

Figure 5. (A) Pictures of the self-healed elastomer P1 and its tensile process. (B) The tensile stressstrain curves of the original and healed P1. (C) The self-healing efficiency of P1. (D) The tensile stress-strain curves of the original and healed P1-Cu-6/1. (E) The self-healing efficiency of P1-Cu-6/1. (RT-room temperature).

In addition to self-healing abilities, both P1 and P1-Cu elastomers also exhibit excellent reprocessability, benefiting from the reversibility of the supramolecular interactions. For the reprocessing experiment, we placed the P1 elastomer pieces in a steel mold and then pressed it at $50^{\circ} \mathrm{C}$ under $4 \mathrm{MPa}$ for $20 \mathrm{~min}$. After cooling to room temperature, the obtained film was cut into dumbbell-shaped samples and subjected to tensile tests to evaluate its mechanical properties (Figure 6A). As shown in Figure 6B, the tensile properties of reprocessed-P1 were found to be nearly the same as those of the original P1, illustrating its excellent reprocessability. Meanwhile, although the metal coordination reduced the mobility, or flexibility, of the main chains, the networks containing metal ions still displayed favorable reprocessing properties. For example, after hot-pressing, the $\sigma_{\max }$ and $\varepsilon_{\mathrm{b}}$ of P1-Cu-6/1 were found to be $1.58 \mathrm{MPa}$ and 334\%, respectively (Figure 6C), which were nearly identical to the original values (1.59 MPa, 337\%). 
(A)

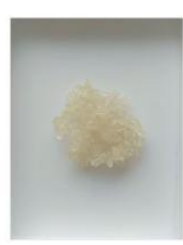

(B)

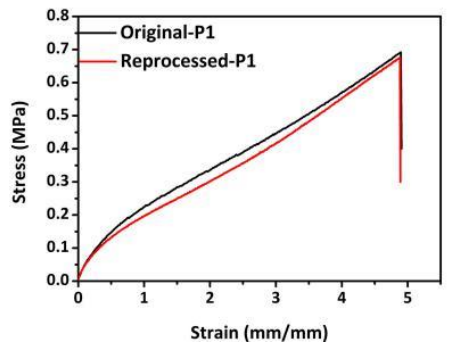

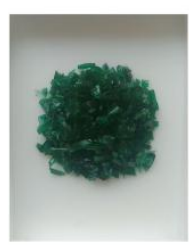

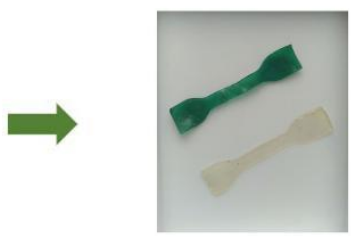

(C)

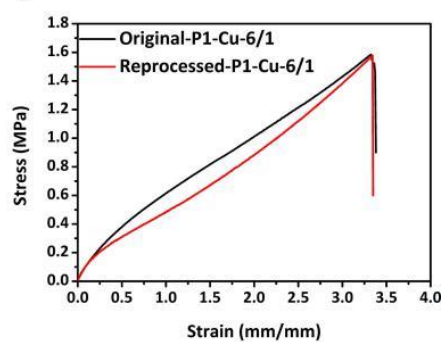

Figure 6. (A) Pictures of samples P1 (white) and P1-Cu-6/1 (blue) before and after hot-pressing at $50{ }^{\circ} \mathrm{C}$ for 20 min under $4 \mathrm{MPa}$. (B) The tensile stress-strain curves of the original and reprocessed P1. (C) The tensile stress-strain curves of the original and reprocessed P1-Cu-6/1.

\subsection{Applications for Photoluminescent and Conductive Supramolecular Elastomers}

Given the integration of robust mechanical strength, superior extensibility, and excellent self-healing capability, both types of supramolecular elastomers show promising potential for use in photoluminescent materials and flexible electronic devices, such as strain sensors.

Lanthanide ions have a long-lived excited state and strong narrow-width emission bands in the visible region resulting from their $\mathrm{f}-\mathrm{f}$ transitions $[31,32]$. Therefore, they are widely used in the preparation of photoluminescent materials such as fluorescent tubes, lasers, field-emission displays, and optical amplifiers. In this study, supramolecular elastomers P1-Eu with a photoluminescence capacity were successfully prepared based on the coordination of $\mathrm{Eu}^{3+}$ ions with the polymer P1. Different amounts of $\mathrm{Eu}\left(\mathrm{NO}_{3}\right)_{3} \cdot 6 \mathrm{H}_{2} \mathrm{O}$ were introduced into the $\mathbf{P 1}$ network to obtain photoluminescent supramolecular elastomers named P1-Eu-x, where the molar ratio of $\mathrm{Eu}\left(\mathrm{NO}_{3}\right)_{3} \cdot 6 \mathrm{H}_{2} \mathrm{O}$ vs. nitrogen atoms in $\mathbf{P 1}$ was $\mathbf{x}$.

Their solid-state fluorescent spectra were measured at the excitation wavelength of $365 \mathrm{~nm}$. As shown in Figure 7A, the three elastomers P1-Eu-4\%, P1-Eu-10\%, and P1-Eu$\mathbf{2 0} \%$ all exhibited the characteristic emission peaks of $\mathrm{Eu}^{3+}$ ions at $591 \mathrm{~nm}$ and $617 \mathrm{~nm}$. The former peak was assigned to the $5 \mathrm{D}_{0} \rightarrow 7 \mathrm{~F}_{1}$ transition of the $\mathrm{Eu}^{3+}$ ions, while the latter resulted from the $5 \mathrm{D}_{0} \rightarrow 7 \mathrm{~F}_{2}$ transition. The emission intensities at 591 and $617 \mathrm{~nm}$ varied with the $\mathrm{N} / \mathrm{Eu}^{3+}$ ratios. In addition, the very strong emission peak at $617 \mathrm{~nm}$ illustrated the highly polarized chemical environment of the $\mathrm{Eu}^{3+}$ ions. As demonstrated above, the P1 elastomer itself would also exhibit the emission at $443 \mathrm{~nm}$ under the excitation of $365 \mathrm{~nm}$. Therefore, the photoluminescent colors of the P1-Eu samples resulted from both the $\mathrm{Eu}^{3+}$ ions and the P1 elastomers. As shown in Figure 7B, the emission color change could be easily observed in the CIE-1931 RGB coordinates, which were calculated from the emission spectra. As the $\mathrm{Eu}^{3+}$ content increased, these materials showed a continuous color change from blue to cyan, and finally, to bright green.

Another potential application of elastomer P1, that is, for use in the production of self-healable electronic devices, was further investigated. A self-healing conductive elastomer, P1-MWCNT, was successfully prepared via the combination of hydrogen-bonded elastomer P1 and multiwalled carbon nanotubes (MWCNT) (Figure 8A; $\sigma_{\max }=1.39 \mathrm{MPa}$, $\varepsilon_{\mathrm{b}}=231 \%$ ). To qualitatively evaluate the electrical conductivity of the P1-MWCNT elastomer, a closed circuit consisting of a piece of P1-MWCNT $\left(20 \times 8 \times 0.7 \mathrm{~mm}^{3}\right)$, a small LED bulb, a regulated power supply $(7 \mathrm{~V})$, and some connecting wires was designed. As shown in Figure 8B, the LED lamp was instantly illuminated by switching on the power supply. When the sample was subjected to a tensile strain of approximately $50 \%$, the 
luminous intensity of the LED lamp dropped correspondingly. When the elastomer was cut in half using a blade, the LED light immediately turned off. However, after the two cut surfaces made contact and self-healed, the LED lamp was again illuminated. Similarly, as the repaired elastomer continued to be stretched, the brightness of the LED lamp decreased due to the increase in resistance.

(A)

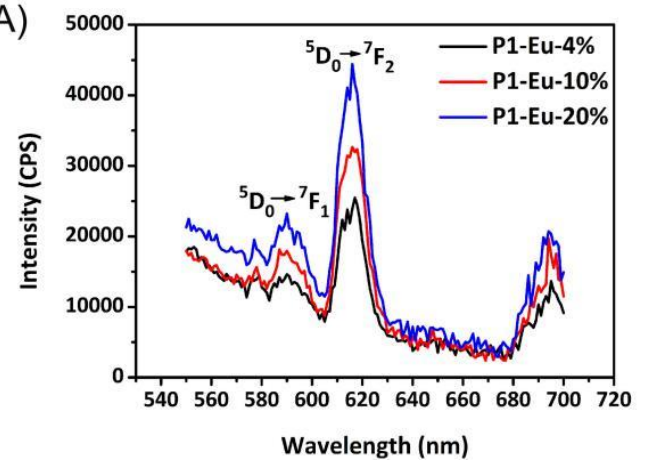

(B)

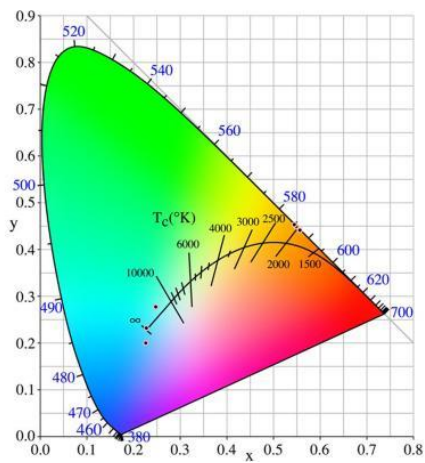

Figure 7. (A) The fluorescence emission spectra of elastomers P1-Eu-4\%, P1-Eu-10\%, and P1-Eu-20\% at the same excitation wavelength $(365 \mathrm{~nm})$. (B) The CIE1931 RGB colorimetric diagram of samples P1-Eu. The small black dots represent the three kinds of P1-Eu samples with different N/Eu ${ }^{3+}$ ratios.

(A)

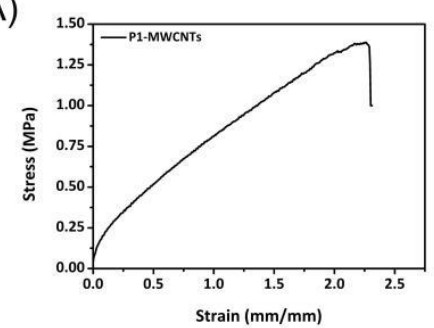

(C)

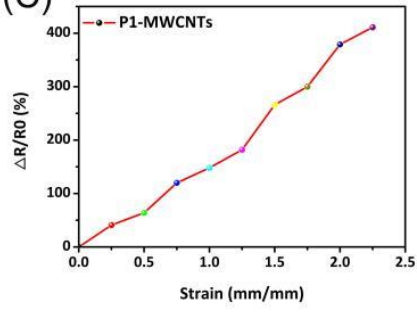

(B)
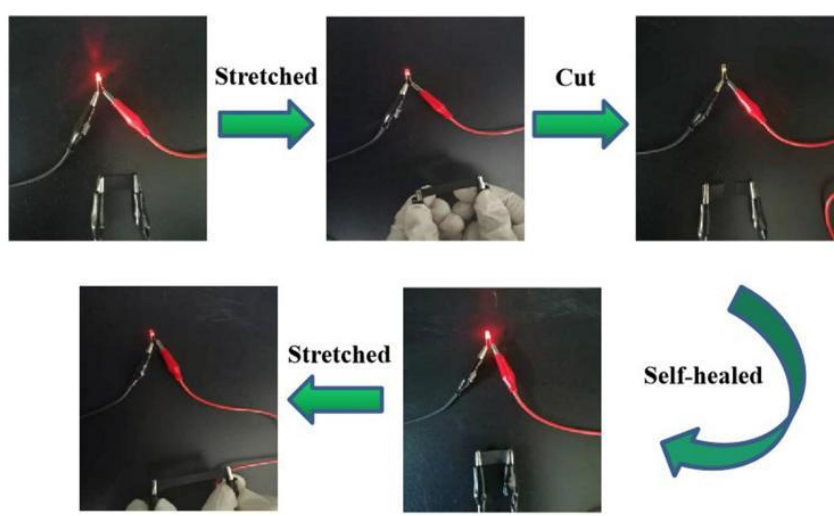

Figure 8. (A) The tensile stress-strain curve of elastomer P1-MWCNT. (B) The LED illumination (7 V) via the P1-MWCNT-based electrical circuit; The LED luminance change during the stretching $\left(\varepsilon_{\mathrm{b}} \approx 50 \%\right.$ ) and damaging processes of the P1-MWCNT; The LED illumination and the response to stretching based on the self-healed elastomer. (C) The change in the electrical resistance of P1MWCNT under different strains: $\Delta R / R_{0}$ value of the P1-MWCNT in response to tensile deformation ( $\triangle \mathrm{R}$ and $\mathrm{R}_{0}$ are the resistance variation upon stretching and the initial resistance, respectively).

Next, to preliminary explore the response behavior of the P1-MWCNT to external strain, a piece of P1-MWCNT with an initial size of $20 \times 8 \times 0.4 \mathrm{~mm}^{3}$ was subjected to various strains to determine the change in resistance as $\Delta R / R_{0} ; \Delta R$ and $R_{0}$ refer to the resistance variation upon stretching and the initial resistance, respectively. Figure $8 \mathrm{C}$ reveals that the measured resistance value gradually increased with the increase in deformation. When the P1-MWCNT was stretched $225 \%$, its $\Delta R / R_{0}$ value reached $410 \%$. It was believed that the tight MWCNT would gradually become loose during the stretching process, which 
would destroy the conductive path and increased the resistance. According to the above results, it is reasonable to conclude that this supramolecular elastomer shows promising potential for future use in flexible strain sensors.

\section{Conclusions}

In summary, we have demonstrated that silicon-containing poly( $\beta$-hydroxyl amine)s synthesized via the polymerization between 1,3-bis(3-glycidyloxypropyl)tetramethyldisiloxane and 3-amino-1,2-propanediol are value building blocks for preparing stretchable, selfhealable, and reprocessable supramolecular elastomers. Among the obtained elastomers, the hydrogen-bonded elastomer exhibits an unconventional fluorescence behavior owing to the unique $\mathrm{Si}-\mathrm{N}$ coordination and displays a low $\mathrm{T}_{\mathrm{g}}$ value resulting from the sufficient flexibility of the siloxane main chains. The mechanical properties of the metal-coordinated elastomers can be flexibly adjusted by varying the molar ratio of $\mathrm{N} / \mathrm{CuCl}_{2}$. Moreover, these elastomers show excellent self-healing properties and hot-pressing reprocessability. Notably, we also prepared photoluminescence-tunable materials and self-healing conductive elastomers by combining the elastomers with $\mathrm{Eu}^{3+}$ and MWCNT, respectively. Considering the facile accessibility, adjusted mechanical properties, and outstanding dynamic capacities, these novel supramolecular elastomers based on poly( $\beta$-hydroxyl amine)s could find application for use as sustainable materials, fluorescent materials, and flexible electronic sensors.

Author Contributions: Conceptualization, L.L. and S.F.; methodology, L.W. and J.Z.; investigation, L.W. and J.Z.; data curation, L.W. and J.Z.; writing—original draft preparation, L.W. and J.Z.; writingreview and editing, L.L.; visualization, L.W. and J.Z.; supervision, L.L. and S.F.; project administration, L.L. and S.F.; funding acquisition, L.W., L.L. and S.F. All authors have read and agreed to the published version of the manuscript.

Funding: This work was supported by the National Natural Science Foundation of China (No. 21901144, 52173102, and 21774070), the Shandong Provincial Natural Science Foundation (ZR2020QB021), the Fundamental Research Funds of Shandong University (No. 2019GN067), the Fluorine Silicone Materials Collaborative Fund of the Shandong Provincial Natural Science Foundation (ZR2021LFG001), the Young Scholars Program of Shandong University, and the Foundation of the Key Laboratory of Special Functional Aggregated Materials.

Institutional Review Board Statement: Not applicable.

Informed Consent Statement: Not applicable.

Data Availability Statement: Not applicable.

Conflicts of Interest: The authors declare no conflict of interest.

\section{References}

1. Kajita, T.; Noro, Y.; Matsushita, A. Design and properties of supramolecular elastomers. Polymer 2017, 128, 297-310. [CrossRef]

2. Sijbesma, R.P.; Beijer, F.H.; Brunsveld, L.; Folmer, B.J.B.; Hirschberg, J.H.K.K.; Lange, R.F.M.; Lowe, J.K.L.; Meijer, E.W. Reversible polymers formed from self-complementary monomers using quadruple hydrogen bonding. Science 1997, 278, 1601-1604. [CrossRef]

3. Hentschel, J.; Kushner, A.M.; Ziller, J.; Guan, Z. Self-healing supramolecular block copolymers. Angew. Chem. Int. Ed. 2012, 51, 10561-10565. [CrossRef]

4. Mozhdehi, D.; Ayala, S.; Cromwell, O.R.; Guan, Z.B. Self-healing multiphase polymers via dynamic metal-ligand interactions. J. Am. Chem. Soc. 2014, 136, 16128-16131. [CrossRef]

5. Li, C.H.; Wang, C.; Keplinger, C.; Zuo, J.L.; Jin, L.; Sun, Y.; Zheng, P.; Cao, Y.; Lissel, F.; Linder, C.; et al. A Highly stretchable autonomous self-healing elastomer. Nat. Chem. 2016, 8, 618-624. [CrossRef]

6. Nomimura, S.; Osaki, M.; Park, J.; Ikura, R.; Takashima, Y.; Yamaguchi, H.; Harada, A. Self-healing alkyl acrylate-based supramolecular elastomers cross-linked via host-guest interactions. Macromolecules 2019, 52, 2659-2668. [CrossRef]

7. Hou, J.B.; Zhang, X.Q.; Wu, D.; Feng, J.F.; Ke, D.; Li, B.J.; Zhang, S. Tough self-healing elastomers based on the host-guest interaction of polycyclodextrin. ACS Appl. Mater. Interfaces 2019, 11, 12105-12113. [CrossRef] [PubMed] 
8. Hart, L.R.; Hunter, J.H.; Nguyen, N.A.; Harries, J.L.; Greenland, B.W.; Mackay, M.E.; Colquhoun, H.M.; Hayes, W. Multivalency in healable supramolecular polymers: The effect of supramolecular cross-link density on the mechanical properties and healing of non-covalent polymer networks. Polym. Chem. 2014, 5, 3680-3688. [CrossRef]

9. Burattini, S.; Greenland, B.W.; Hayes, W.; Mackay, M.E.; Rowan, S.J.; Colquhoun, H.M. A supramolecular polymer based on tweezer-type $\pi-\pi$ stacking interactions: Molecular design for healability and enhanced toughness. Chem. Mater. 2011, 23, 6-8. [CrossRef]

10. Itano, M.; Kobayashi, Y.; Takashima, Y.; Harada, A.; Yamaguchi, H. Mechanical properties of supramolecular polymeric materials cross-linked by donor-acceptor interactions. Chem. Commun. 2019, 55, 3809-3812. [CrossRef] [PubMed]

11. Yi, B.; Liu, P.; Hou, C.; Cao, C.; Zhang, J.; Sun, H.; Yao, X. Dual-cross-linked supramolecular polysiloxanes for mechanically tunable, damage-healable and oil-repellent polymeric coatings. ACS Appl. Mater. Interfaces 2019, 11, 47382-47389. [CrossRef] [PubMed]

12. Wu, X.; Wang, J.; Huang, J.; Yang, S. Robust, Stretchable, and self-healable supramolecular elastomers synergistically cross-linked by hydrogen bonds and coordination bonds. ACS Appl. Mater. Interfaces 2019, 11, 7387-7396. [CrossRef] [PubMed]

13. Zhang, Q.; Niu, S.; Wang, L.; Lopez, J.; Chen, S.; Cai, Y.; Du, R.; Liu, Y.; Lai, J.C.; Liu, L.; et al. An elastic autonomous self-healing capacitive sensor based on a dynamic dual crosslinked chemical system. Adv. Mater. 2018, 30, 1801435. [CrossRef]

14. Tian, M.; Zuo, H.; Wang, J.; Ning, N.; Yu, B.; Zhang, L. A silicone elastomer with optimized and tunable mechanical strength and self-healing ability based on strong and weak coordination bonds. Polym. Chem. 2020, 11, 4047-4057. [CrossRef]

15. Kobayashi, Y.; Hirase, T.; Takashima, Y.; Harada, A.; Yamaguchi, H. Self-healing and shape-memory properties of polymeric materials cross-linked by hydrogen bonding and metal-ligand interactions. Polym. Chem. 2019, 10, 4519-4523. [CrossRef]

16. Li, C.H.; Zuo, J.L. Self-healing polymers based on coordination bonds. Adv. Mater. 2020, 32, 1903762. [CrossRef] [PubMed]

17. Liu, K.; Kang, Y.; Wang, Z.; Zhang, X. 25th Anniversary article: Reversible and adaptive functional supramolecular materials: "non-covalent interaction" matters. Adv. Mater. 2013, 25, 5530-5548. [CrossRef]

18. Wang, S.; Urban, M.W. Self-healing polymers. Nat. Rev. Mater. 2020, 5, 562-583. [CrossRef]

19. Saha, A.; De, S.; Stuparu, M.C.; Khan, A. Facile and general preparation of multifunctional main-chain cationic polymers through application of robust, efficient, and orthogonal click chemistries. J. Am. Chem. Soc. 2012, 134, 17291-17297. [CrossRef]

20. Yu, J.; Su, Z.; Xu, H.; Ma, X.; Yin, J.; Jiang, X. One-pot approach to synthesize hyperbranched poly(thiol-ether amine) (hPtEA) through sequential "thiol-ene" and "epoxy-amine" click reactions. Polym. Chem. 2015, 6, 6946-6954. [CrossRef]

21. Wilfong, W.C.; Kail, B.W.; Bank, T.L.; Howard, B.H.; Gray, M.L. Recovering rare earth elements from aqueous solution with porous amine-epoxy networks. ACS Appl. Mater. Interfaces 2017, 9, 18283-18294. [CrossRef] [PubMed]

22. Zhang, G.; Zhao, Q.; Yang, L.; Zou, W.; Xi, X.; Xie, T. Exploring dynamic equilibrium of diels-alder reaction for solid state plasticity in remoldable shape memory polymer network. ACS Macro Lett. 2016, 5, 805-808. [CrossRef]

23. Oh, J.; Jung, K.I.; Jung, H.W.; Khan, A. A modular and practical synthesis of zwitterionic hydrogels through sequential amineepoxy "click" chemistry and n-alkylation reaction. Polymers 2019, 11, 1491. [CrossRef] [PubMed]

24. Zhou, J.; Wang, L.; Li, L.; Feng, S. Novel clickable and fluorescent poly(siloxane amine)s for reusable adhesives and reprocessable elastomers. Polym. Chem. 2020, 11, 4780-4786. [CrossRef]

25. Wang, Z.; Urban, M.W. Facile UV-healable polyethylenimine-copper (C2H5N-Cu) supramolecular polymer networks. Polym. Chem. 2013, 4, 4897-4901. [CrossRef]

26. Dai, Y.; Zhang, X.; Zhuo, R. Polymeric micelles stabilized by polyethylenimine-copper $\left(\mathrm{C}_{2} \mathrm{H}_{5} \mathrm{~N}-\mathrm{Cu}\right)$ coordination for sustained drug release. RSC Adv. 2016, 6, 22964-22968. [CrossRef]

27. Lu, H.; Feng, L.; Li, S.; Zhang, J.; Lu, H.; Feng, S. Unexpected strong blue photoluminescence produced from the aggregation of unconventional chromophores in novel siloxane-poly(amidoamine) dendrimers. Macromolecules 2015, 48, 476-482. [CrossRef]

28. Cao, J.; Zuo, Y.; Lu, H.; Yang, Y.; Feng, S. An unconventional chromophore in water-soluble polysiloxanes synthesized via thiol-ene reaction for metal ion detection. J. Photochem. Photobiol. A 2018, 350, 152-163. [CrossRef]

29. Zhang, L.Z.; Liu, Z.H.; Wu, X.L.; Guan, Q.B.; You, Z.W. A highly efficient self-healing elastomer with unprecedented mechanical properties. Adv. Mater. 2019, 31, 1901402. [CrossRef]

30. Mureseanu, M.; Puscasu, M.; Somacescu, S.; Carja, G. CuII(sal-ala)/CuAlLDH hybrid as novel efficient catalyst for artificial superoxide dismutase (SOD) and cyclohexene oxidation by $\mathrm{H}_{2} \mathrm{O}_{2}$. Catal. Lett. 2015, 145, 1529-1540. [CrossRef]

31. Yang, C.Y.; Srdanov, V.; Robinson, M.R.; Bazan, G.C.; Heeger, A.J. Orienting Eu(dnm)3phen by tensile drawing in polyethylene: Polarized Eu3+ emission. Adv. Mater. 2002, 14, 980-983. [CrossRef]

32. Xu, L.; Li, Y.; Pan, Q.; Wang, D.; Li, S.; Wang, G.; Chen, Y.; Zhu, P.; Qin, W. Dual-mode light-emitting lanthanide metal-organic frameworks with high water and thermal stability and their application in white LEDs. ACS Appl. Mater. Interfaces 2020, 12, 18934-18943. [CrossRef] [PubMed] 